\title{
Fungal S-adenosylmethionine synthetase and the control of development and secondary metabolism in Aspergillus nidulans
}

\author{
Jennifer Gerke, Özgür Bayram, Gerhard H. Braus* \\ Institut für Mikrobiologie Er Genetik, Georg-August-Universität, Grisebachstr. 8, D-37077 Göttingen, Germany
}

\section{A R T I C L E I N F O}

\section{Article history:}

Received 13 December 2011

Accepted 12 April 2012

Available online 26 April 2012

\section{Keywords:}

S-adenosylmethionine synthetase

Methylation

Aspergillus nidulans

Sexual development

Secondary metabolism

Tandem affinity purification

\begin{abstract}
A B S T R A C T
The filamentous fungus Aspergillus nidulans carries a single gene for the $\underline{S}$-addenosylmethionine (SAM) synthetase SasA, whereas many other organisms possess multiple SAM synthetases. The conserved enzyme catalyzes the reaction of methionine and ATP to the ubiquitous methyl group donor SAM. SAM is the main methyl group donor for methyltransferases to modify DNA, RNA, protein, metabolites, or phospholipid target substrates. We show here that the single A. nidulans SAM synthetase encoding gene sasA is essential. Overexpression of $s a s A$, encoding a predominantly cytoplasmic protein, led to impaired development including only small sterile fruiting bodies which are surrounded by unusually pigmented auxiliary Hülle cells. Hülle cells are the only fungal cell type which does not contain significant amounts of SasA. Sterigmatocystin production is altered when sasA is overexpressed, suggesting defects in coordination of development and secondary metabolism. SasA interacts with various metabolic proteins including methionine or mitochondrial metabolic enzymes as well as proteins involved in fungal morphogenesis. SasA interaction to histone-2B might reflect a putative epigenetic link to gene expression. Our data suggest a distinct role of SasA in coordinating fungal secondary metabolism and development.
\end{abstract}

(c) 2012 Elsevier Inc. All rights reserved.

\section{Introduction}

S-adenosylmethionine synthetase (EC 2.5.1.6) is the only known enzyme that catalyzes the synthesis of S-adenosylmethionine (SAM) from methionine with ATP (Tabor and Tabor, 1984). SAM was discovered by Catoni (1953) and since then extensively investigated, especially in mammals as it is proposed to have therapeutic benefits in human diseases (Chiang et al., 1996). Besides ATP, the ubiquitous enzyme substrate SAM is one of the most frequently used substrates and the major methyl group donor in all living organisms. It is involved in methylation processes of DNA, RNA, proteins, metabolites, and phospholipids, in which the methyl group is transferred by a methyltransferase to the corresponding substrate (Mato et al., 1997). About 15 methyltransferase superfamilies have been identified and their classifications are based on substrate specificity rather than sequence similarities (Loenen, 2006).

SAM is the major cellular methyl donor but acts also as monoalkyl donor or 5'-deoxyadenosyl radical source. It is involved in a variety of processes in different organisms such as protection of

\footnotetext{
* Corresponding author. Address: Institute of Microbiology and Genetics, Department of Molecular Microbiology and Genetics, Georg-August-University, Grisebachstr. 8, D-37077 Göttingen, Germany. Fax: +49 551393330.

E-mail addresses: jgerke@gwdg.de (J. Gerke), obayram@gwdg.de (Ö. Bayram), gbraus@gwdg.de (G.H. Braus).
}

bacterial DNA, function of restriction enzymes, bacterial chemotaxis, regulation of gene expression, cellular differentiation, stress response, biosynthesis of secondary metabolites (e.g. polyketides or non-ribosomal peptides), virus latency, mRNA export, efficient translation and protection of mRNA integrity (Chiang et al., 1996). In addition, it is the sole carboxy-aminopropyl donor for the synthesis of polyamines, like spermidine. SAM is involved in the production of modified nucleotides in rRNA, or acts as transcriptional regulator by binding to riboswitches (Bjork et al., 1987; Bowman et al., 1973; Corbino et al., 2005; McDaniel et al., 2005; Winkler and Breaker, 2005).

SAM synthetases have been extensively studied in bacteria, yeasts, plants and mammals including humans (Cai et al., 1996; Peleman et al., 1989; Porcelli et al., 1988; Sakata et al., 1993; Thomas and Surdin-Kerjan, 1987), but less is known about them in filamentous fungi. SAM synthetases are highly conserved between bacteria and eukaryotes, with lower conservation in archaea (Graham et al., 2000). Escherichia coli or Schizosaccharomyces pombe possess one SAM synthetase, Saccharomyces cerevisiae and humans carry two isoforms, whereas there are even four isoenzymes in the plant Arabidopsis thaliana or the fly Drosophila melanogaster.

The catalytic reaction of SAM synthetase occurs in a two-step reaction. First, the triphosphate is cleaved from ATP and further hydrolyzed to $\mathrm{PP}_{\mathrm{i}}$ and $\mathrm{P}_{\mathrm{i}}$ before SAM is released (Mudd and Cantoni, 1958). The first crystal structure of the SAM synthetase MetK of 
E. coli was determined in 1996 (Takusagawa et al., 1996a). MetK consists of four identical subunits forming two dimers among which the active sites lie. The triphosphate moiety interacts extensively with the amino acid residues in the active site of the enzyme in order to cleave it at both ends, while the adenine and ribose moiety show weak interaction, what facilitates the release of SAM (Takusagawa et al., 1996b). After methyl group donation Sadenosylhomocysteine is formed, which is hydrolyzed further to homocysteine and adenosine.

Misregulation of the SAM synthetase encoding genes leads to changes in growth in several bacteria or the yeast $S$. pombe, and to changes in growth and secondary metabolism in the plant $A$. thaliana. In contrast, the filamentous fungus Neurospora crassa shows no phenotypical changes when expression of SAM synthetase encoding genes is changed (Belbahri et al., 2000; Hilti et al., 2000; Mautino et al., 1996; Newman et al., 1998; Ochi and Freese, 1982).

Aspergillus nidulans represents a model organism for filamentous fungi where development is coordinated to secondary metabolism. The life cycle is light-dependent. During illumination, primarily green asexual spores (conidia) are formed on conidiophores, whereas the sexual structures are repressed by light and primarily formed in dark and under limited oxygen levels (Adams et al., 1998; Bayram et al., 2010; Braus et al., 2010, 2002; Purschwitz et al., 2008). The closed sexual fruiting bodies (cleistothecia) are surrounded by nursing Hülle cells (Sarikaya Bayram et al., 2010) and contain the red ascospores. Light is sensed by photoreceptors that transmit the signal to recipients like the velvet regulators. In the dark, the velvet protein VeA is transported together with the second velvet-like protein VelB into the nucleus, where they can form together with the putative methyltransferase LaeA the trimeric VelB-VeA-LaeA complex which coordinates sexual development and secondary metabolism (Bayram and Braus, 2011; Bayram et al., 2008). A. nidulans LaeA is required for secondary metabolite expression of the sterigmatocystin (ST) or penicillin clusters (Bok and Keller, 2004; Bok et al., 2006). An additional role of LaeA is its requirement for Hülle cell formation (Sarikaya Bayram et al., 2010). LaeA carries a conserved SAM-binding site typical for nuclear protein methyltransferases (Bok and Keller, 2004; Kozbial and Mushegian, 2005) and there is accumulating evidence for an epigenetic control function of LaeA by chromatin remodeling (Reyes-Dominguez et al., 2010). A misregulation of the SAM synthetase encoding gene in A. nidulans might therefore affect development and secondary metabolism.

We analyzed the function of the single SAM synthetase SasA in the filamentous fungus $A$. nidulans for metabolism, growth, morphogenesis, development and secondary metabolism. We used genetic, cell biological and biochemical tools to obtain a comprehensive picture of the essential cellular function of SasA.

\section{Experimental procedures}

\subsection{Strains and growth conditions}

Strains used in this study are listed in Table S3. A. nidulans strains were cultivated on minimal medium $\left(0.52 \mathrm{~g} \mathrm{l}^{-1} \mathrm{KCl}\right.$, $0.52 \mathrm{~g} \mathrm{l}^{-1} \mathrm{MgSO}_{4}, 1.52 \mathrm{~g} \mathrm{l}^{-1} \mathrm{KH}_{2} \mathrm{PO}_{4}, 0.1 \%$ trace element solution, pH 6.5, (Barratt et al., 1965) or on CMM medium (minimal medium with $0.1 \%$ casein hydrolysate) at $30^{\circ} \mathrm{C}$ or $37^{\circ} \mathrm{C}$ and supplemented appropriately with $1 \mu \mathrm{g} \mathrm{ml}^{-1}$ pyridoxine- $\mathrm{HCl}, 1 \mu \mathrm{g} \mathrm{ml} \mathrm{g}^{-1}$ uracil, $0.25 \mu \mathrm{g} \mathrm{ml}^{-1}$ uridine, $1 \mu \mathrm{g} \mathrm{ml}^{-1}$ pyrithiamine (Takara Bio Inc, Münsing, Germany), $120 \mu \mathrm{g} \cdot \mathrm{ml}^{-1}$ nourseothricin-dihydrogen sulfate (clonNAT, Werner BioAgents, Jena, Germany). $10 \mathrm{mM}$ nitrate, ammonium or proline served as nitrogen source and $1 \%$ D-glucose as carbon source. For solid medium, 2\% agar was added. For vegetative growth, cultures were cultivated in light in submerged medium, for induction of asexual development, cultures were grown in light on solid medium, and for induction of sexual development, cultures were grown in dark on solid medium under oxygen limiting conditions (Clutterbuck, 1974). E. coli strains were propagated in LB medium (1\% tryptone, $0.5 \%$ yeast extract, $1 \%$ $\mathrm{NaCl}$ ).

\subsection{Strain construction and generation of transformation cassettes}

Strains generated in this study are listed in Table S3. Plasmids and primers used in this study are given in Tables S4 and S5.

For overexpression strain AGB665, the nitrogen source driven promoter ${ }^{p}$ niiA, amplified from pME3160 with primers JG92/93, and $p t r A$, amplified from pPTRII with primers JG21/22, were fused via fusion PCR. The $1 \mathrm{~kb}$ upstream flanking region of sas $A$ and $1.3 \mathrm{~kb}$ of $s a s A$ were amplified with primers JG83/150 and JG151/ 147 and fused to the ptrA:: ${ }^{p}$ niiA cassette with primers JG84/152. The resulting cassette was subsequently cloned into strain TNO2A3 via homologous recombination.

For deletion of sasA the upstream and downstream flanking regions were amplified with primers JG47/48 and JG49/50 from genomic DNA and fused to ptrA with primers JG51/52. The deletion cassette was transformed into strain TNO2A3 via homologous recombination.

The C-terminally GFP- and TAP-tagged SasA strains AGB666 and AGB667 were generated by transformation via homologous recombination in strain TNO2A3. For both strains the $0.8 \mathrm{~kb}$ upstream flanking region and sasA were amplified with primers JG83/85 (GFP) or JG83/89 (TAP) and the $0.8 \mathrm{~kb}$ downstream flanking region was amplified with primers JG86/88 from genomic DNA. Subsequently, the amplicons were cloned to the gfp::gpdA::nat ${ }^{R}$ or ctap::gpdA::nat ${ }^{R}$ cassette, respectively, with primers JG84/87. For generation of cassettes, gfp was cloned to ${ }^{p}$ gpdA::nat ${ }^{R}$ (amplified from plasmid pNV1) with oligos OZG192/207 and ctap with OZG192/209. For generation of AGB668 and AGB669, strains AGB666 and AGB667 were crossed with wild type strain AGB154. For construction of the double tap strain veA::ctap/velB::ctap (AGB677), the strains veA::ctap (AGB273) and velB::ctap (AGB389) were crossed.

\subsection{Transformation procedures}

A. nidulans transformations were performed by polyethylene glycol mediated fusion of protoplasts as described previously (Eckert et al., 2000; Punt and van den Hondel, 1992).

\subsection{Heterokaryon rescue}

Heterokaryon rescue was performed according to the protocol by Osmani (Nayak et al., 2006). First, primary transformants of a standard $A$. nidulans transformation were picked and plated on selective and non-selective medium. Second, a primary transformant was excised together with agar, put on an agar plate with selective medium and grown 3 days at $30^{\circ} \mathrm{C}$. A fresh agar piece was cut out, put in liquid selective medium and grown for 3 days at $30^{\circ} \mathrm{C}$. Mycelia were harvested and genomic DNA extracted. Diagnostic PCR was performed with primers JG59/60.

\subsection{Extraction of genomic DNA}

Mycelia of vegetative grown cultures were ground in liquid nitrogen and lysed in appropriate buffer ( $50 \mathrm{mM}$ Tris ( $\mathrm{pH} 7.2$ ), $50 \mathrm{mM}$ EDTA, $30 \mathrm{~g} \mathrm{l}^{-1} \mathrm{SDS}, 10 \mathrm{ml} \mathrm{l}^{-1} \beta$-mercaptoethanol) at $65^{\circ} \mathrm{C}$. Genomic DNA was extracted twice with phenol/chloroform (1:1 $(\mathrm{v} / \mathrm{v}))$ and subsequently precipitated with isopropanol and 
$50 \mathrm{mM}$ sodium acetate (Kolar et al., 1988). Genomic DNA was dissolved in RNAse treated EB buffer (Qiagen, Hilden, Germany) and stored at $4{ }^{\circ} \mathrm{C}$.

\subsection{Southern hybridization}

Southern hybridization was performed according to standard protocols (Busch et al., 2003) with nonradioactively labeled probes (Amersham Bioscience, Buckinghamshire, UK). For probe preparations, DNAs were amplified from genomic DNA by PCR using primers listed in Tables S5 and S6.

\subsection{Extraction of RNA}

RNA was extracted from vegetative, asexual and sexual grown cultures. For vegetative cultures, the strain was grown 14 and $20 \mathrm{~h}$ in liquid medium at $37^{\circ} \mathrm{C}$. For asexual and sexual cultures, the strain was grown $20 \mathrm{~h}$ in liquid medium and the obtained mycelium was transferred to solid medium and grown 24, 48, and $72 \mathrm{~h}$ in light or dark at $37^{\circ} \mathrm{C}$. For Northern experiments, mycelia were ground in liquid nitrogen and mixed with Trizol (Invitrogen GmbH, Karlsruhe, Germany) and chloroform. After centrifuging, the upper phase was extracted twice with phenol/ chloroform $(1: 1(\mathrm{v} / \mathrm{v}))$. Total RNA was precipitated with isopropanol overnight, dissolved in 0.1\%-DEPC-water and stored at $-20^{\circ} \mathrm{C}$. For quantitative real-time PCR, after grinding of mycelia in liquid nitrogen, total RNA was extracted with the RNEasy Plant Kit (Qiagen, Hilden, Germany).

\subsection{Northern hybridization}

Northern hybridization was performed according to the protocol of Brown and Mackey (1997). The gel was loaded with $10 \mu \mathrm{g}$ RNA. DNA for probe was amplified from genomic DNA with primers JG147/151. The probe was labeled with $\left[\alpha^{-}{ }^{32} \mathrm{P}\right]$-dATP using the Prime-It ${ }^{\circledR}$-II kit (Stratagene Europe, Amsterdam, Nederlands) (Feinberg and Vogelstein, 1983). Autoradiographs were produced using BioMaxMS films (Kodak Molecular Imaging, New Haven, CT, USA).

\subsection{Quantitative real-time $P C R$}

DNase digestion and subsequent cDNA synthesis was carried out with the QuantiTect Reverse Transcription Kit (Qiagen, Hilden, Germany) with $0.8 \mathrm{mg}$ of RNA for each sample. Amplification was performed in a LightCycler 2.0 (Roche) with the RealMaster SYBR Rox Kit (5Prime) using $1 \mathrm{ml}$ of the cDNA and $A$. nidulans primers JG385/386 and RT H2A $5^{\prime}(+) / 3^{\prime}(-)$ (Table S5). The constitutively expressed $\mathrm{H} 2 \mathrm{~A}$ encoding gene was used for normalization and a sample without cDNA served as additional control. Amplification conditions were as follows: 36 cycles of $15 \mathrm{~s}$ at $95^{\circ} \mathrm{C}, 22 \mathrm{~s}$ at $64{ }^{\circ} \mathrm{C}, 22 \mathrm{~s}$ at $70^{\circ} \mathrm{C}$, and an adjacent melting step $\left(42-95^{\circ} \mathrm{C}\right)$. The amount of sasA relative to histone H2A RNA was quantified using the DCT method with efficiency (Pfaffl et al., 2002). All real-time PCR experiments were performed in triplicate.

\subsection{Fluorescence microscopy}

A. nidulans strains (2000 spores) were inoculated in eight chambered borosilicate coverglass system (NUNC) supplemented with liquid medium or on glass slides covered with a thin layer of medium and incubated at $30^{\circ} \mathrm{C}$. Fluorescence photographs were taken with an AXIOVERT OBSERVER. Z1 (ZEISS) microscope equipped with a QUANTEM:512SC (PHOTOMETRICS) digital camera and the SLIDEBOOK 5.0 software package (INTELLIGENT IMAGING INNOVATIONS).

\subsection{Protein extraction and Western blot}

For isolation of proteins, crude extracts from vegetative grown cultures were prepared by grinding mycelia and extracting proteins with $\mathrm{B} 300$ buffer ( $100 \mathrm{mM}$ Tris- $\mathrm{HCl}, \mathrm{pH} 7.5,300 \mathrm{mM} \mathrm{NaCl}$, $10 \%$ glycerol, 2 mM EDTA, pH 8 ) at $4{ }^{\circ} \mathrm{C}$ with addition of Complete Protease Inhibitor Cocktail (Roche, Mannheim, Germany). After centrifugation, the supernatant was directly used for further analyses.

For Western experiments, the protein extracts were separated by PAGE and transferred onto a nitrocellulose membrane by electroblotting. As first antibody Anti-Calmodulin Binding Protein Epitope Tag (Biomol, Hamburg, Germany) and as second antibody goat-anti-rabbit IgG HRP (MoBiTec, Göttingen, Germany) was used. Prestained PageRuler (Fermentas GmbH, St. Leon-Rot, Germany) was utilized as marker. As detection reagent, the ECL technology (GE Healthcare Life Sciences, Munich, Germany) products were used.

\subsection{Tandem affinity purification (TAP)}

Vegetative cultures were grown over night at $30^{\circ} \mathrm{C}$ in liquid medium and the mycelia were shifted to solid CMM medium (minimal medium with $0.1 \%$ casein hydrolysate) and grown under asexual or sexual inducing conditions. TAP experiments were performed as described previously (Bayram et al., 2008) with the TAP-tagged protein strain and the untagged wild type strain as control. In addition to the standard protocol, modified purifications were performed. For fixation of proteins, $28 \mathrm{ml} \mathrm{l}^{-1}$ formaldehyde was added after $20 \mathrm{~h}$ of vegetative growth. After $20 \mathrm{~min}$ of incubation, $2.5 \mathrm{M}$ glycine was added, and after $5 \mathrm{~min}$, cultures were harvested as described before. A second modification included changes in buffer composition and concentration. Buffers were used without phosphatase inhibitors and instead of IPP300 the buffer IPP150 was used twice during washing steps. 4-8 $\mu \mathrm{M}$ Sadenosylmethionine was added to all buffers. In a shortened purification, directly after washing with IPP150, glycine buffer $(0.1 \mathrm{M}$ glycine, $150 \mathrm{mM} \mathrm{NaCl}, 0.1 \%$ Triton X-100, pH 2) was added. Proteins were eluted after 5 min of incubation and precipitated with trichloroacetic acid.

\subsection{3. $L C-M S / M S$ protein identification}

Polyacrylamide gel pieces of stained protein bands were digested with trypsin according to Shevchenko et al. (1996). Tryptic peptides were extracted and identified using reversed-phase liquid chromatography coupled with an LCQ DecaXP mass spectrometer (ThermoElectron Corp., San Jose, CA) equipped with a nanoelectrospray ion source (Bayram et al., 2008).

\subsection{Analysis of sterigmatocystin}

For analysis of sterigmatocystin, plates were inoculated with $10^{7}$ spores and grown 3 days at $37^{\circ} \mathrm{C}$. An agarpiece $(\varnothing=1.5 \mathrm{~cm})$ was homogenized in $3 \mathrm{ml}$ water and subsequently extracted with an equivalent volume of chloroform. The organic phase was evaporated and the residual metabolites were dissolved in $50 \mu \mathrm{l}$ methanol. $15 \mu \mathrm{l}$ of the extract was separated on TLC in acetone/ chloroform 4:1 (v/v) and derivatized with an alcoholic aluminum chloride solution $(20 \%(\mathrm{w} / \mathrm{v}))$. Metabolites were visualized under $\lambda=366 \mathrm{~nm}$. As standard, sterigmatocystin (Sigma-Aldrich Chemie $\mathrm{GmbH}$, Steinheim, Germany) was used. The data were documented using CAMAG TLC Visualizer (CAMAG, Muttenz, Switzerland). 


\section{Results}

3.1. A. nidulans genome contains one SAM synthetase gene with conserved motifs

In A. nidulans the SAM synthetase encoding gene AN1222 consists of 1278 nucleotides (with two introns in the N-terminal region) encoding a putative protein with 388 amino acids and a predicted molecular mass of $42.2 \mathrm{kDa}$. According to the A. nidulans nomenclature we named the gene as $\operatorname{sas} A$ ( $\underline{\text { S-adenosylmethionine }}$ synthetase $\underline{A}$ ). The deduced amino acid sequence of SasA exhibits two conserved motifs typical for all SAM synthetases (Fig. 1A). At the beginning of the central domain the hexapeptide GAGDQG is present, which binds the adenine moiety of ATP (Pajares et al., 1991). In the C-terminal domain the glycine-rich nonapeptide GGGAFSGKD is present. This motif forms a P-loop-like structure and is proposed to be involved in binding the triphosphate of ATP (Takusagawa et al., 1996b).

A ClustalW alignment of the predicted protein sequence of SasA with other filamentous fungi, yeast, bacteria, plant, human and fly SAM synthetases revealed high similarities between the different species. The identity to other Aspergilli varies between $87 \%$ and 93\%. Interestingly, all Aspergillus species carry only one SAM synthetase encoding gene, except for Aspergillus flavus and Aspergillus oryzae. These organisms possess two independent isoforms with only $55 \%$ identity to each other. They form a separate group in a phylogenetic comparison (Fig. 1B), indicating that these proteins have evolved to perform a different function. Likewise, S. cerevisiae possesses two independent SAM synthetase encoding genes SAM1 and SAM2. However, the encoded proteins show a high amino acid identity of $91 \%$ to each other. In human, the identity between the two existing isoforms MAT1A and MAT2A is $84 \%$. In D. melanogaster

A.nidulans
A.clavatus
A.flavus 1
A.flavus 2
A. fumigatus
A.niger
A. oryzae 1
A. oryzae 2
E. coli
S. cerevisiae Sam1
S. cerevisiae Sam2
N. crassa
H. sapiens MAT1A
H.sapiens MAT2A
D.melanogaster 1
D.melanogaster 2
D.melanogaster 3
D.melanogaster 4
A. thaliana 1
A. thaliana 2
A. thaliana 3
A. thaliana 4

114 LHYEEALEKLGAGDQGIMFGY . . GWGAHGGGAFSGKDYSKVD 284

113 LHYDEALEKLGAGDQGIMFGY ... GWGAHGGGAFSGKDYSKVD 284

116 LHYDEALEKLGAGDQGIMFGY . . . GWGAHGGGAFSGKDYSKVD 286

110 SSGLEAPDDEPAGDOGMAFGY . . GWGAHGGGAFSGKDFROVD 280

113 LHYDEALEKLGAGDOGIMFGY ... GWGAHGGGAFSGKDYSKVD 283

113 LHYEEALEKLGAGDQGIMFGY . . . GWGAHGGGAFSGKDYSKVD 283

116 LHYDEALEKLGAGDQGIMFGY . . . GWGAHGGGAFSGKDYSKVD 286

110 SSGLEAPDDEPAGDQGMAFGY . . .GWGAHGGGAFSGKDFRQVD 280

106 GVDRADPLEQGAGDQGLMFGY . . . GMARHGGGAFSGKDPSKVD 272

108 VHEEKDLEDIGAGDQGIMFGY. . . GASSVGGGAFSGKDYSKVD 278

110 LHYEKSLEDLGAGDQGIMFGY . . . GASSVGGGAFSGKDYSKVD 280

120 LHLDDRLENLGAGDQGIMFGY . . . GWGAHGGGAFSGKDFSKVD 290

121 VHLDRNEEDVGAGDQGLMFGY . . . GWGAHGGGAFSGKDYTKVD 291

121 VHLDRNEEDIGAGDQGLMFGY... GWGAHGGGAFSGKDYTKVD 291

132 VHINREEEDVGAGDQVSISKR. . .----------------

132 VHVNRAEEEIGAGDQGIMFGY ... GWGAHGGGAFSGKDFTKVD 302

132 VHINREEEDVGAGDQGIMFGY. . .GWGAHGGGAFSGKDFTKVD 302

105 VHINREEEDVGAGDQGIMFGY . . . GWGAHGGGAFSGKDFTKVD 275

109 GHFTKCPEEIGAGDQGHMFGY... GWGAHGGGAFSGKDPTKVD 279

109 GHFFKRPEDIGAGDQGHMFGY . . GWGAHGGGAFSGKDPTKVD 279

109 GHLTKKPEDIGAGDQGHMFGY . . GWGAHGGGAFSGKDPTKVD 279

109 GHLTKKPEEVGAGDQGHMFGY . . GWGAHGGGAFSGKDPTKVD 279
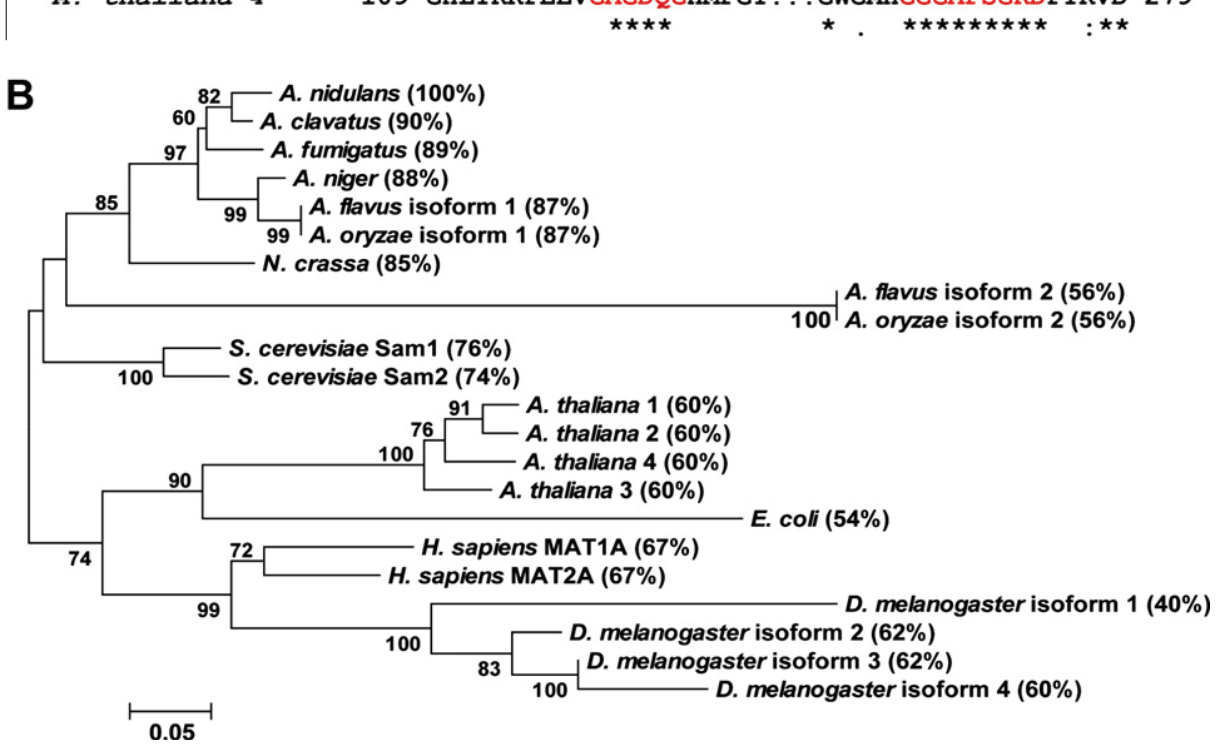

Fig. 1. Comparison of SAM synthetases from different organisms. (A) Protein comparison of SAM synthetases from different organisms. The conserved motifs are shown in red. GenBank Accession numbers for sequences are: Aspergillus nidulans (CBF87906), Aspergillus clavatus (EAW07774), Aspergillus flavus isoforms 1 and 2 (EED50079, EED51490), Aspergillus fumigatus (EDP56296), Aspergillus niger (CAK45307), Aspergillus oryzae isoforms 1 and 2 (BAE64158, BAE62029), Escherichia coli (CAH56923), Saccharomyces cerevisiae Sam1 and Sam2 (AAB67461, AAB64944), Neurospora crassa (AAC49260), Homo sapiens MAT1A and MAT2A (BAA08355, CAA48726), Drosophila melanogaster isoforms 1-4 (AAF51558, AAF51555, AAF51556, AAF51557), Arabidopsis thaliana isoforms 1-4 (AEE27438.1, AEE82085.1, AEC09311.1, AEE75948.1). (B) The phylogenetic tree was constructed using the Neighbor-Joining method (Saitou and Nei, 1987). The percentages of replicate trees in which the associated taxa clustered together in the bootstrap test (1000 replicates) are shown next to the branches (Felsenstein, 1985). The tree is drawn to scale, with branch lengths in the same units as those of the evolutionary distances used to infer the phylogenetic tree. The evolutionary distances were computed using the number of differences method (Nei and Kumar, 2000) and are in the units of the number of amino acid differences per sequence. Evolutionary analyses were conducted in MEGA5 (Tamura et al., 2011 ). Protein identities to A. nidulans SasA are given in parentheses. 
four SAM synthetase isoforms exist. Isoforms 2-4 have identities of 93-97\% to each other, and only the shorter isoform 1 differs highly with identities of $55-75 \%$ to isoforms $2-4$.

The identity of $A$. nidulans SasA to the isoforms of $D$. melanogaster is $40-62 \%$, the identity to the human isoforms $67 \%$, to yeast Sam 1 and Sam2 74-76\%, to E. coli MetK 54\%, and to the filamentous fungus $N$. crassa protein $85 \%$. The evolutionary correlation is summarized in a phylogenetic tree (Fig. 1B). These data show that higher eukaryotes such as fly and human possess multiple copies of SAM synthetases, while fungi show variability in copy number between one and two.

\subsection{The sasA gene is highly expressed during vegetative growth}

We analyzed the expression of sasA during different developmental stages. Northern analysis was performed with RNA extracted from vegetative, asexual and sexual cultures grown for different time periods (Fig. 2A). For verification of the Northern results, we additionally performed real-time PCR (Fig. S1). The results show that sasA is strongly expressed during vegetative growth and that expression is downregulated during development in asexual or sexual grown cultures.

We compared the mRNA levels with the production of the SasA protein. A functional tap-tagged sasA strain was constructed (Fig. S2). Production of the tagged protein was monitored at the same stages of development as the transcripts by Western blot analysis with an anti-calmodulin binding protein antibody, recognizing the calmodulin binding peptide of the TAP-tag (Fig. 2B). Western results showed that SasA is strongly produced at vegetative stages and at early developmental stages, but production decreases during asexual and sexual development. Summarizing, mRNA expression and SasA protein production are correlating.

\subsection{Constitutively expressed sasA is essential for the viability of A. nidulans}

SAM is one of the most commonly used enzyme substrates and the major methyl group donor in all living organisms. Therefore, the deletion of the single sasA gene should be lethal, except there is a second, yet not identified SAM synthetase encoding gene in the genome of $A$. nidulans, which can compensate its function. We addressed whether sasA is essential by constructing a pyrithiamine resistance marker ( $p t r A)$ containing deletion cassette and integrated it into the genome of an A. nidulans wild type strain homologously (Fig. 3A). We obtained 18 primary transformants, which did not grow while generating single colonies.
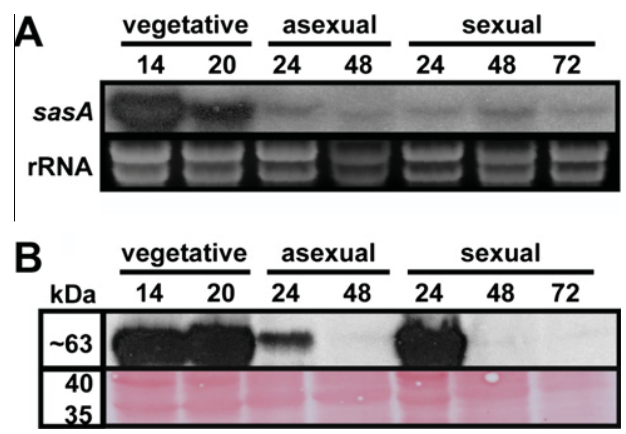

Fig. 2. Expression of $s a s A$ in A. nidulans. (A) Northern hybridization of sasA during vegetative, asexual, and sexual development. Cultures were grown for $14,20,24$ 48 , and $72 \mathrm{~h}$. rRNA levels were used as loading control. (B) Western Blot analysis of C-terminally TAP-tagged SasA. Protein extracts were prepared after 14, 20, 24, 48, and $72 \mathrm{~h}$ of vegetative, asexual, and sexual growth. Ponceau staining is shown as loading control.
To proof whether sasA is essential, we applied the heterokaryon rescue technique (Nayak et al., 2006). First, a growth test on selecting and non-selecting medium was performed (Fig. 3B). The primary transformants grew on non-selecting medium, but they did not grow on selecting medium containing pyrithiamine, indicating the existence of a heterokaryon with a wild type $s a s A$ gene $\left(s a s A^{+}\right.$, $p t r A^{-}$) and the deletion $\left(s a s A^{-}, p t r A^{+}\right)$. Second, a diagnostic PCR was carried out using genomic DNA extracted from the heterokaryon (Fig. 3C). One primer annealing to the 5'-UTR region of the deletion cassette and one primer annealing in the genome directly behind the deletion cassette were chosen. The primer selection theoretically results in PCR products of $3.5 \mathrm{~kb}$ for the wild type $\left(\mathrm{sas}^{+}\right.$, $\left.p t r A^{-}\right)$and $4.2 \mathrm{~kb}$ for the deletion event $\left(s a s A^{-}, p t r A^{+}\right)$. The diagnostic PCR showed double bands at 3.5 and $4.2 \mathrm{~kb}$ for almost all clones, proving the existence of a heterokaryon. These results corroborate that the sasA gene is essential and its functions are indispensable for the cellular activities of $A$. nidulans.

\subsection{Overexpression of sasA leads to sterile microcleistothecia with pigmented Hülle cells}

We then addressed whether SasA production, which is primarily observed during vegetative development and at initial stages of fungal development, has a major impact on development of $A$. nidulans. We cloned sasA under the inducible niiA/niiD promoter. The correct homologous integration of the cloning cassette was verified by Southern hybridization experiments (Fig. S2). For verification of overexpression, the relative sasA mRNA abundance was determined by quantitative real-time PCR with primers for sasA cDNA under inducing conditions. The results show a 2.3-fold increase in sasA mRNA level compared to wild type mRNA (Fig. 4A).

For expression studies, wild type and sasA overexpressing (OE) strain were grown on different inducing and repressing media. Growth on nitrate medium induces the specific niiA/niiD transcription factor and thus sasA expression, whereas growth on the universal repressor ammonium reduces activity of the general nitrogen source transcription factor areA and therefore reduces sasA expression (Arst and Cove, 1973; Punt et al., 1995). Both strains were grown on inducing nitrate medium $\left(\mathrm{NO}_{3}^{-}\right)$, inducing and repressing proline, nitrate and ammonium medium (proline $+\mathrm{NH}_{4}^{+}+\mathrm{NO}_{3}^{-}$), repressing proline and ammonium medium (proline $+\mathrm{NH}_{4}^{+}$) and noninducing and nonrepressing proline medium. The developmental defects were analyzed during asexual and sexual growth.

During asexual development, sasA expression had impact on conidiation and colony diameter (Fig. 4B). While under inducing conditions $\left(\mathrm{NO}_{3}^{-}\right)$, conidiation is rather similar to wild type, under inducing and repressing conditions (proline $+\mathrm{NH}_{4}^{+}+\mathrm{NO}_{3}^{-}$) the amount of conidia is diminished to $25 \%$ of wild type level (Fig. 4C) and the colony diameter was reduced to 20\% (Fig. 4D). As the sas $A$ deletion results indicated, under repressing conditions (proline $+\mathrm{NH}_{4}^{+}$) the sasA mutant did not grow. Under noninducing plus nonrepressing conditions (proline) the mutant had a normal colony diameter, but produced nearly no conidia and additionally synthesized red pigments.

The sexual life cycle was drastically affected by sasA overexpression. The mutant was not able to perform its normal sexual life cycle. Under inducing conditions $\left(\mathrm{NO}_{3}^{-}\right)$the mutant strain generated very few and very small cleistothecia (microcleistotecia) with a diameter of $40-50 \mu \mathrm{m}$ after 10 days of growth compared to normal wild type cleistothecia with a diameter of 100-200 $\mu \mathrm{m}$ (Fig. 5A and $\mathrm{B})$. In addition, these microcleistothecia were sterile, lacking fertile ascospores. Concludingly, A. nidulans was not able to reproduce sexually when sasA was overexpressed.

Although only very few cleistothecia were developed, the amount of nursing Hülle cells was unaffected during sexual devel- 
A

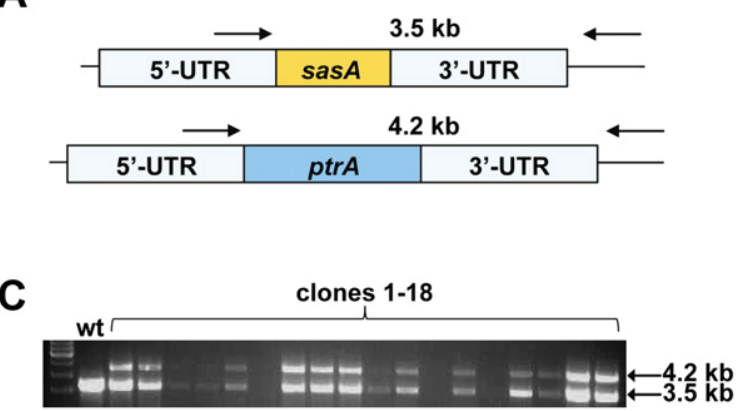

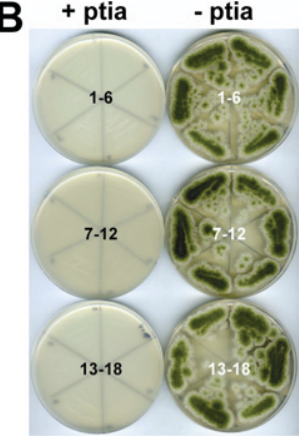

Fig. 3. Deletion of $s a s A$ is lethal. (A) Construction of sasA deletion. sasA was replaced by a pyrithiamine resistance marker (ptrA) via homologous recombination. Arrows indicate primers used for heterokaryon rescue PCR. For wild type locus a PCR amplicon of $3.5 \mathrm{~kb}$ and for deletion strain locus a PCR amplicon of $4.2 \mathrm{~kb}$ was expected. (B) Growth of primary transformants 1-18 was tested on selecting pyrithiamine (+ ptia) and non-selecting ( - ptia) medium. (C) Diagnostic PCR with DNA extracted from primary transformants 1-18. Primers given in Fig. 3A were used. For wild type DNA, a band of $3.5 \mathrm{~kb}$ was detected, for clones $1-18$ DNA, a double band of $3.5 \mathrm{~kb}$ and $4.2 \mathrm{~kb}$ was detected, proving the existence of a heterokaryon.

opment. The Hülle cells, which normally do not contain significant amounts of SasA (see Section 3.6), were remarkably different in comparison to wild type because they accumulated a pink colored pigment. Under inducing and repressing conditions (proline $+\mathrm{NH}_{4}^{+}+\mathrm{NO}_{3}^{-}$) and under noninducing and nonrepressing conditions (proline) no sexual structures were formed and under repressing conditions (proline $+\mathrm{NH}_{4}^{+}$) the mutant did not grow.

\subsection{Overexpression of sasA leads to reduced production of sterigmatocystin}

As overexpression of sasA had a possible impact on secondary metabolism indicated by the red color produced on proline medium (Fig. 4B), we analyzed whether overexpression influenced biosynthesis of the well-studied aflatoxin precursor sterigmatocystin (ST). Initially, we tested expression of genes for the transcription factor aflR and the ketoreductase $s t c U$, which are involved in ST biosynthesis, the master regulator of secondary metabolism laeA and the penicillin and terrequinone A producing ipnA and tdiA with Northern hybridization. Our results showed no significant changes in expression levels in sasA OE in comparison to wild type strain (data not shown).

We further analyzed whether there are posttranscriptional ef fects, which might influence secondary metabolism. Therefore, we extracted the non-polar metabolites from asexual grown wild type and sasA OE cultures and determined the amount of produced ST with thin-layer chromatography (TLC, Fig. 5C). Our results showed that production of ST in sasA OE strain is significantly reduced compared to wild type.

\subsection{SasA is predominantly localized to the cytoplasm in most fungal cell types except Hülle cells}

In S. cerevisiae, the SAM synthetases Sam 1 and Sam2 are both primarily localized in the cytoplasm (Kumar et al., 2002). We determined the subcellular localization of the A. nidulans SasA via fluorescence microscopy. Therefore, sgfp (synthetic green fluorescent protein) was fused to sasA and integrated into the genome of $A$. nidulans homologously (Fig. S2). The construct was expressed under the native promoter of sasA.

Fluorescence microscopy revealed that SasA is primarily localized in the cytoplasm (Fig. 6A). SasA is not restrictively localized during asexual development to a distinct cell type but is visible in the cytoplasm of entire conidiophores including the conidiospores. During sexual development, SasA is localized to the ascospores but not to the Hülle cells, which are the nursing cells surrounding the cleistothecium (Sarikaya Bayram et al., 2010).
Predominant cytoplasmic localization of SasA::GFP fusion indicates that SasA functions in the cytoplasm whereas any activity in other compartments might be only due to small SasA subpopulations.

\subsection{Protein interaction studies revealed involvement of SasA in methionine metabolism and fungal growth}

Protein interaction studies were performed for a more comprehensive picture of SasA function in the fungal cell. The tandem affinity purification (TAP) was applied using the SasA::TAP fusion strain (Fig. S2). The protein interactions were determined in extracts obtained from vegetative, asexual, or sexual grown cultures. In addition, an untagged wild type strain was analyzed under the same conditions as a control to exclude unspecific protein bindings. The purified protein extracts were separated on a SDS polyacrylamide gel. A protein band with an expected molecular weight for SasA of approximately $42 \mathrm{kDa}$ was detectable (Fig. 6B).

During TAP analysis 22 putative interaction partners of SasA were identified via mass spectrometry (Table 1 and Table S1, ribosomal proteins were not listed). We further divided the identified proteins into subcategories. Three proteins (AN10474, AN4443, and AN8224) are connected to metabolism of the SAM synthetase substrate methionine. A second group spans proteins, which are putatively localized to the mitochondria in eukaryotes. An aconitase and a malate dehydrogenase were identified that are involved in citrate cycle. Additionally to the malate dehydrogenase, we found an aspartate aminotransferase. The respective homologous proteins in S. cerevisiae act together in malate-aspartate shuttle to transport NADH from cytoplasm into mitochondria (Easlon et al., 2008). The AN8216 homolog nucleoside diphosphate kinase Ynk1 of yeast, which catalyzes the transfer of gamma phosphates from nucleoside triphosphates to nucleoside diphosphates, is also partially localized to mitochondria in yeast (Amutha and Pain, 2003).

A third group of proteins putatively interacting with SasA are involved in gluconeogenesis. Phosphoenolpyruvate carboxykinase, catalyzing the GTP-dependent reaction of oxaloacetate to phosphoenolpyruvate, is a key enzyme in this reaction cascade. The fructose-bisphosphate aldolase catalyzes the conversion of fructose 1,6-bisphosphate to glyceraldehyde-3-phosphate and dihydroxyacetone-phosphate. Gluconeogenesis is an important process as it allows organisms to grow on different carbon sources than sugar, like glycerol or ethanol (Haarasilta and Oura, 1975).

The fourth group comprises proteins, which are involved in fungal morphogenesis. This includes cell division, growth or cell wall growth. In this group are the conserved cytoskeletal elements tubulin and actin (Pruyne and Bretscher, 2000; Schatz et al., 


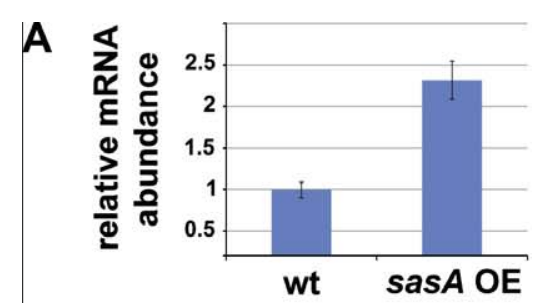

B

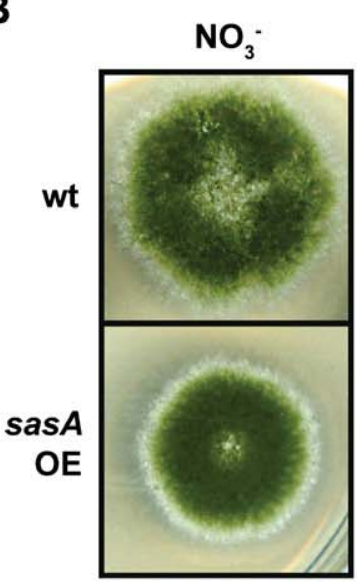

C
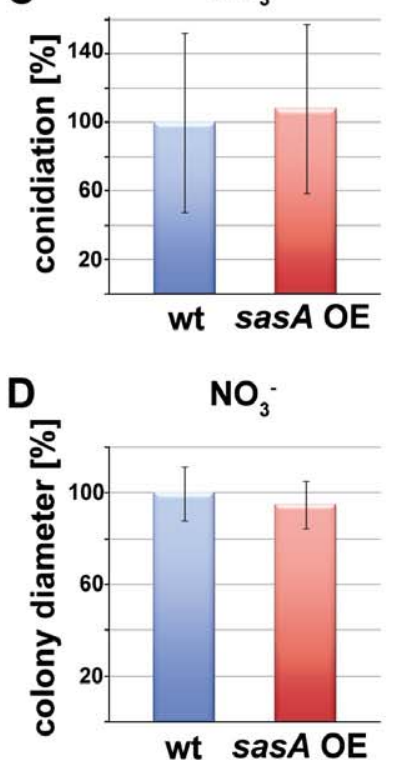

proline + $\mathrm{NO}_{3}{ }^{-}+\mathrm{NH}_{4}^{+}$

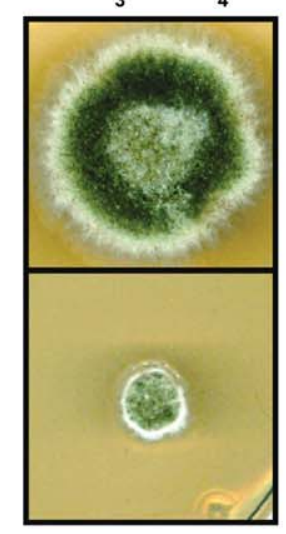

proline + $\mathrm{NH}_{4}^{+}$
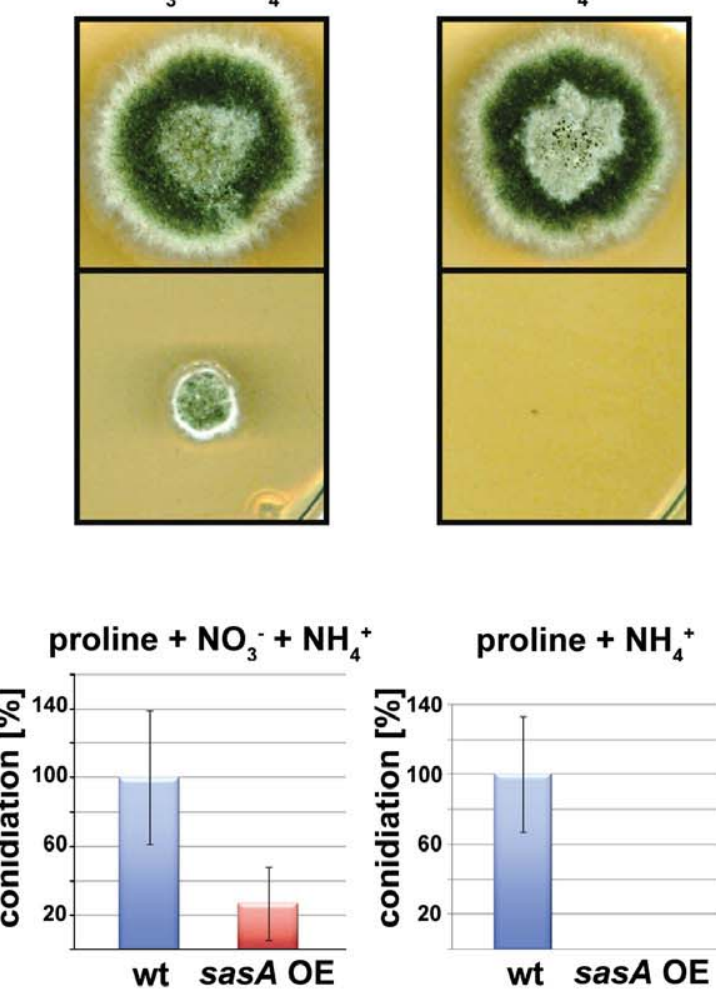

proline $+\mathrm{NO}_{3}^{-}+\mathrm{NH}_{4}^{+}$

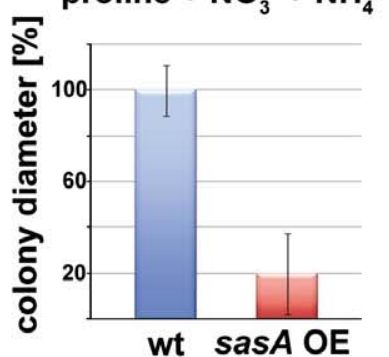

proline $+\mathrm{NH}_{4}{ }^{+}$
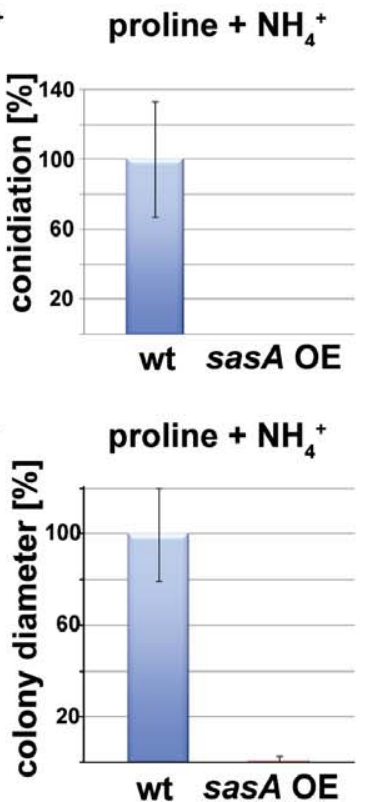

proline

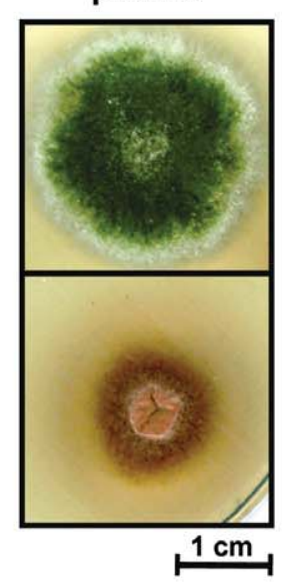

proline

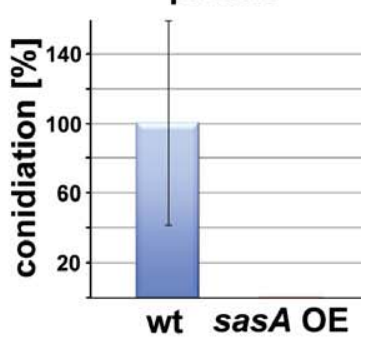

proline

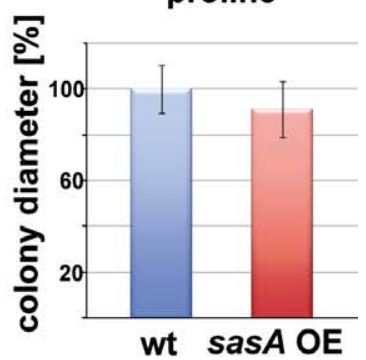

Fig. 4. Modified sasA expression in A. nidulans. (A) Relative mRNA levels of wild type and sasA OE strain measured by quantitative real-time PCR with primers specific for sasA cDNA. Cultures were grown in submerged cultures for $20 \mathrm{~h}$ at $37^{\circ} \mathrm{C}$. Normalization was carried out with primers for histone H2A. The delta CT method including efficiencies was used for quantification. (B) Growth test of sasA OE strain. sasA is under control of the inducible nitrate reductase promoter, which is induced by nitrate ( $\mathrm{NO}_{3}^{-}$), induced and repressed by medium containing proline, ammonium and nitrate (proline $+\mathrm{NH}_{4}^{+}+\mathrm{NO}_{3}^{-}$), repressed by proline and ammonium (proline $+\mathrm{NH}_{4}^{+}$) and noninduced and nonrepressed by proline. Strains were grown 3 days at $37^{\circ} \mathrm{C}$ in light for analysis of asexual development. (C) Spore quantification of sasA OE compared to wild type. Wild type levels were set to $100 \%$. (D) Colony diameter of sasA OE colonies compared to wild type. Wild type diameter was set to $100 \%$.

1986), and calmodulin A which regulates many processes including response to various stress conditions, mating, budding, and actin-based processes (Cyert, 2001). The GTP-binding yeast protein Bud4 (homologous to AN6150) is involved in bud-site selection and required for axial budding pattern (Chant and Herskowitz, 1991; Sanders and Herskowitz, 1996) and Qri1 (homologous to AN9094) is important in e.g. cell wall biosynthesis (Cid et al., 1995).
Two proteins are putative stress proteins, like the heat shock protein AN10202 (homologous to Ssa1p in yeast), or the GABA transaminase (AN2248), which homologous protein in yeast is involved in oxidative stress response (Coleman et al., 2001). We identified histone-2B as the only histone which could be an interaction partner of SasA. Four additional putative SasA interacting proteins (other proteins) could not be obviously assigned to a specific category. 


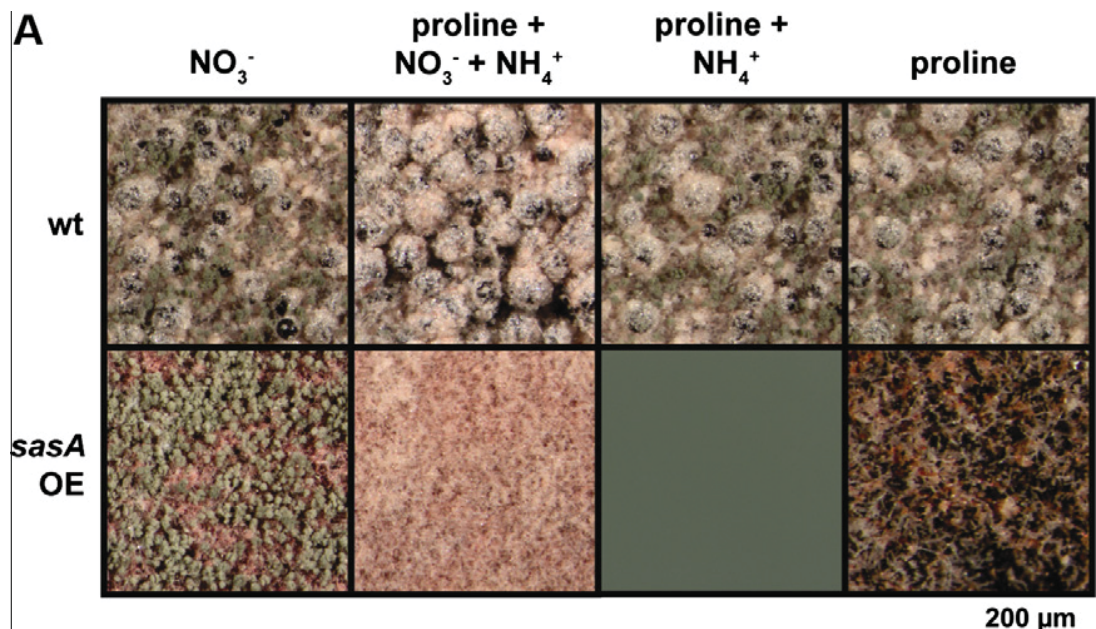

B

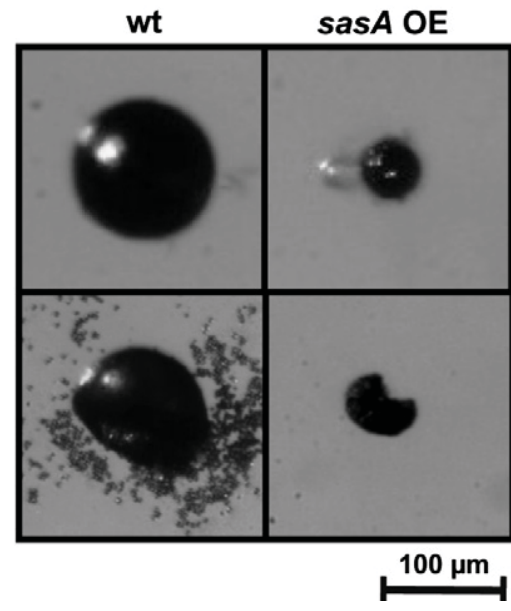

C ST SasA

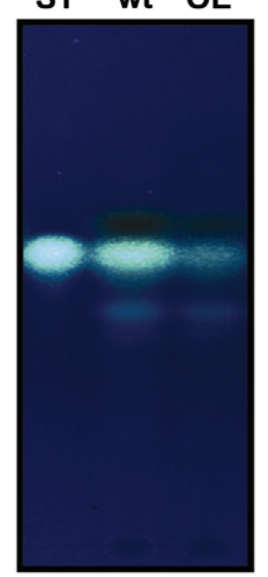

Fig. 5. Sexual development and secondary metabolism in sasA OE strain. (A) Phenotypes of wild type and sas $\mathrm{A}$ OE strains after 7 days of sexual development on nitrate ( $\mathrm{NO}_{3}^{-}$) proline, ammonium and nitrate (proline $+\mathrm{NH}_{4}^{+}+\mathrm{NO}_{3}^{-}$), proline and ammonium (proline $+\mathrm{NH}_{4}^{+}$) and proline containing medium. (B) Cleistothecia of wild type and sasA OE strain after 10 days of sexual growth on nitrate containing medium are shown. (C) Sterigmatocystin production levels of sasA OE and wild type were analyzed with TLC. Agar plates were inoculated with $10^{7}$ spores and grown 3 days at $37^{\circ} \mathrm{C}$. Metabolites were extracted from defined agar pieces, separated on TLC (chloroform/acetone 4:1) and visualized with an alcoholic aluminum chloride solution at $366 \mathrm{~nm}$. Sterigmatocystin (ST) was used as standard.

The putative methyltransferase LaeA is part of the trimeric velvet complex and coordinates sexual development and secondary metabolism. Sequence analysis showed that SasA possesses a SAM-binding motif (Bok and Keller, 2004). When a single subunit of the velvet complex was tagged the SasA protein could never be recruited. The velvet complex could only recruit SasA when a double tap-tagged veA::ctap/velB::ctap strain was used. Besides the already known interaction partners VosA and LaeA, we could also identify the SAM synthetase SasA as putative interaction partner of the velvet complex (Table S2). SasA was detected in a protein extract of sexual grown veA::ctap/velB::ctap cultures after $32 \mathrm{~h}$ of development, but not in the wild type control. Unfortunately, SasA could only be identified in one round of purification. These findings suggest a weak and presumably only transient interaction of SasA with the velvet complex.

\section{Discussion}

SAM synthetases catalyze the synthesis of the major methyl group donor SAM and represent highly conserved proteins which are present in one or more isoforms within a cell. SasA was analyzed in this study and represents the only SAM synthetase of the filamentous fungus A. nidulans. The related A. flavus or A. oryzae possess two putative isoenzymes with only $55 \%$ amino acid identity, whereas the two $S$. cerevisiae isoenzymes are closely related with an identity of $91 \%$. The single SAM synthetase gene sasA of A. nidulans is essential as it was also shown for the corresponding single sam 1 gene of the fission yeast S. pombe (Hilti et al., 2000). In organisms with two SAM synthetase encoding genes, like S. cerevisiae, the deletion of one gene can be compensated by the other, and both genes need to be deleted to achieve lethality (Cherest and Surdin-Kerjan, 1978).

Overexpression of sas $A$ had a strong impact on development and secondary metabolism in the filamentous fungus $A$. nidulans. This was surprising because overexpression of the SAM synthetase encoding gene ETH1 of the filamentous fungus $N$. crassa led to no phenotypical changes in growth rate or morphogenesis (Mautino et al., 1996). In the yeast S. pombe, low expression of sam1 reduced growth, mating and sporulation, while overexpression led to methionine sensitive growth which could be partially suppressed by addition of adenine (Hilti et al., 2000). Misregulated SAM synthetase encoding genes also affect plants where overexpression and suppression of Arabidopsis thaliana sam1 in tobacco led to yellow leaves, reduced plant height, necrotic lesions, and stunted plants with an altered secondary metabolism. Overexpression of 

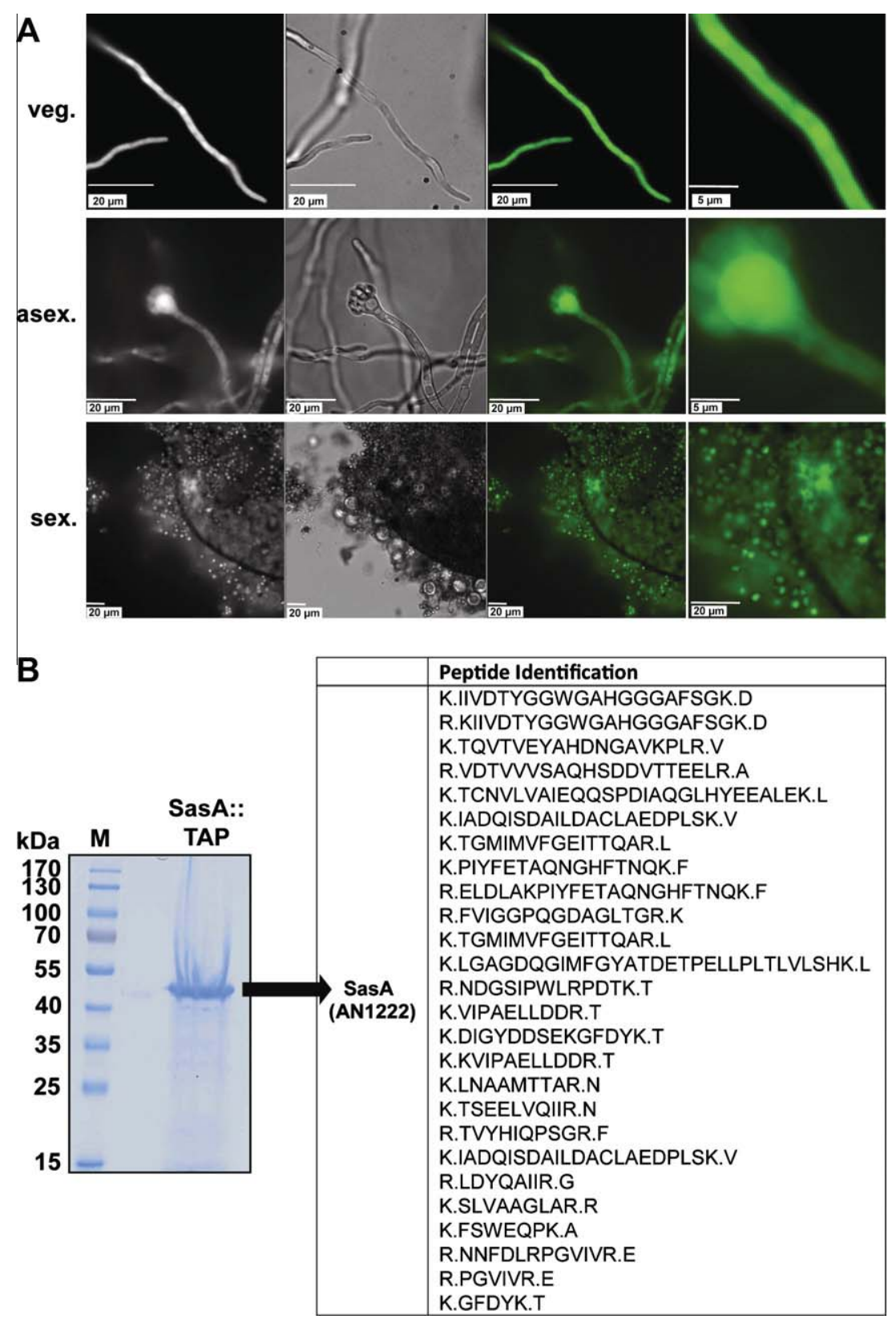

Fig. 6. Localization and protein interaction studies of SasA. (A) Localization of C-terminally GFP-tagged SasA was determined via fluorescence microscopy. Strains were cultivated in liquid medium for vegetative growth and on solid medium with and without light for asexual and sexual development, respectively. SasA is localized to the cytoplasm. (B) C-terminally TAP tagged SasA was purified via tandem affinity purification (TAP). SasA with a size of approximately 42 kDa was detected on SDS polyacrylamide gel. Peptides of SasA identified in mass spectrometry are given. A complete list of all detected proteins is given in Table S1.

sam1 enhanced nicotine and nornicotine biosynthesis whereas reduced expression caused the production of volatiles as methanethiol (Belbahri et al., 2000; Boerjan et al., 1994). SAM synthetase overproduction in the bacterium Bacillus subtilis results in increased spontaneous sporulation (Ochi and Freese, 1982). Low expression of the SAM synthetase encoding $E$. coli gene metK resulted in in the formation of filaments due to blocked septal ring formation (Newman et al., 1998; Wang et al., 2005). Only organisms which possess SAM feedback-inhibited SAM synthetases showed no overexpression phenotypes (Cabrero et al., 1988; Corrales et al., 1992, 1991; Duce et al., 1988; Markham et al., 1983; Thomas and Surdin-Kerjan, 1991; Yarlett et al., 1993). The corresponding A. nidulans or S. pombe enzymes are not feedback-regulated (Hilti et al., 2000; Pieniazek et al., 1973). Exogenously added methionine induced sasA expression in A. nidulans and drastically increased the intracellular SAM levels in S. pombe. Feedback-inhibition might therefore serve as a protective mechanism in numerous organisms.

SasA interaction to other proteins was analyzed by tandem affinity purification (TAP), which allows identifying large relatively stable protein complexes (Bayram et al., 2008; Gavin et al., 2002). This might include proteins which only indirectly interact with SasA if several proteins of the same metabolic or developmental pathway form large complexes. SAM synthetases catalyze the reaction from methionine to SAM. This is consistent with the co-purification of SasA with proteins involved in methionine metabolism which might cooperate. Similarly, the S. cerevisiae glutamyl-tRNA synthetase Gus1 forms a complex with the methionyl- and glutamyl-tRNA synthetase cofactor Arc1 (Deinert et al., 2001; Galani et al., 2001). SasA interaction partners include presumably not only 
Table 1

Putative interaction partners of Aspergillus nidulans SasA identified by tandem affinity purification (TAP). Proteins were purified from vegetative (V), asexual (A), and sexual (S) samples. Homologous proteins in Saccharomyces cerevisiae are given.

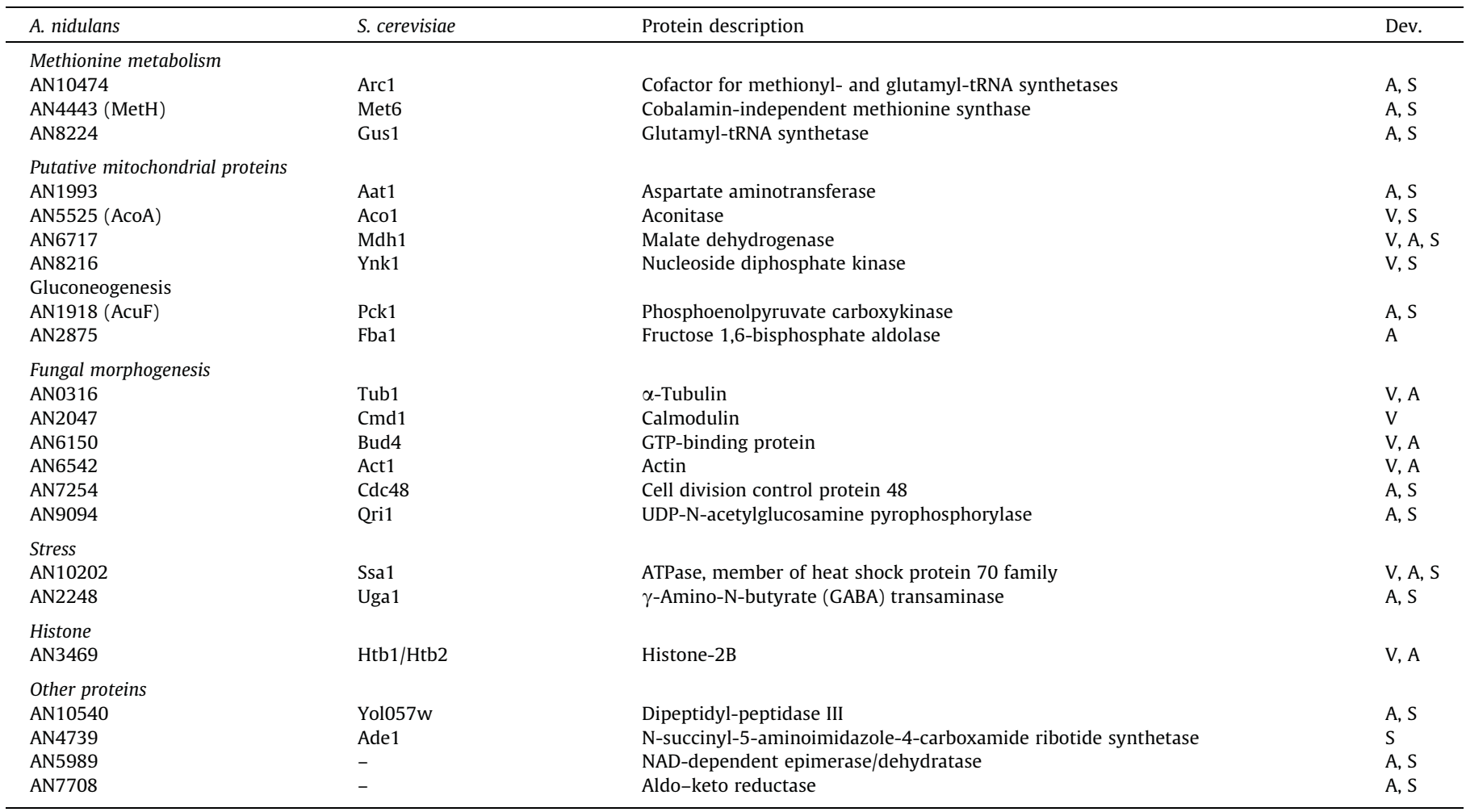

methylation targets but also associated proteins. Future bimolecular fluorescence complementation (BiFC) or yeast-two-hybrid studies will discriminate between direct and indirect SasA interaction partners listed in Table 1.

Similar to yeast, SasA of A. nidulans is primarily localized to the cytoplasm, whereas mitochondrial or nuclear subpopulations are significantly less pronounced. A yeast mitochondrial carrier protein Sam5 transports SAM from cytoplasm to mitochondria, where it is needed for biotin biosynthesis (Marobbio et al., 2003). SasA interaction candidates include mitochondrial proteins involved in citrate cycle or in the malate-aspartate shuttle. It is currently unclear whether the interaction of these proteins with SasA occurs outside of the mitochondria or reflects small mitochondrial SasA subpopulations.

mRNA and protein levels of SasA are high during vegetative growth and early development of $A$. nidulans. The identified interaction partners (Fig. 7) suggest multiple cellular roles of SasA. Early stages of development require changes in morphogenesis and an increased cell division rate. The developmental overexpression phenotypes including colony diameter, spore production and viability suggest that either vegetative and early developmental production of SasA or changes in the availability of the co-factor SAM can affect fungal morphogenesis.

This is further supported by the identified putative SasA interaction partners. As found for A. nidulans, yeast Sam1 also recruits proteins required for morphogenesis like the aconitase Aco1 or $\alpha$-tubulin Tub1 (Gavin et al., 2006). In addition, the recruitment of the cobalamin-independent methionine synthetase Met6 (Malkowski et al., 2007) and the heat shock protein Ssa1 (Gong et al., 2009) seem to be conserved. Heat shock proteins are methylated in response to stress (Chiang et al., 1996). Yeast Aco1 interacts with calmodulin Cmd1 (Krogan et al., 2006), which itself interacts with actin Act1 (Collins et al., 2007) and the nucleoside diphosphate kinase Ynk1 (Ho et al., 2002). All these data support that yeast Sam1

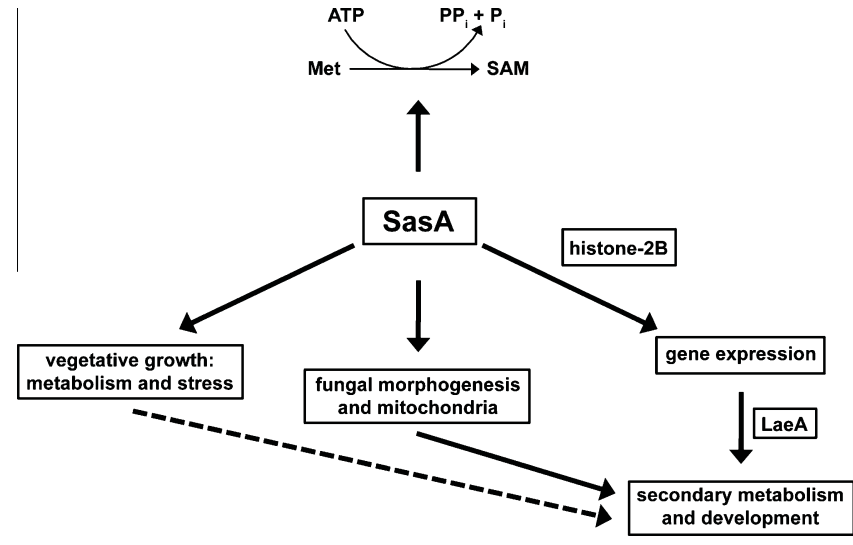

Fig. 7. Proposed model for SasA actions in Aspergillus nidulans. SasA catalyzes the biosynthesis of SAM from methionine (Met) and ATP. Expression of SasA has impact on metabolism and stress response during vegetative growth, on fungal morphogenesis including spore production, colony diameter and sexual fruiting body formation, and on mitochondrial processes. Additionally, it might be involved in coordination of development and secondary metabolism by regulating gene expression

and $A$. nidulans SasA seem to (directly or indirectly) interact with multiple protein partners.

SAM-dependent methyltransferases were not detected as possible interaction partners of SasA by TAP purification. SAM synthetase interactions with methyltransferases were also not detected in the yeast proteome (Gavin et al., 2006). The putative methyltransferase LaeA possesses a conserved SAM binding motif which is typical for nuclear protein methyltransferases (Bok and Keller, 2004). LaeA is part of the VelB-VeA-LaeA complex which coordinates development and secondary metabolism. Single TAP-tagged VelB or VeA did not recruit SasA, but a strain where both velvet 
domain proteins were TAP-tagged could recruit SasA (Table S2). A possible explanation might be a transient interaction between SasA and the VelB-VeA-LaeA complex which might explain why sas $A$ overexpression results in defects in the coordination of secondary metabolism and development. Additional experiments need to be performed to verify the putative interaction. Consistently, sasA overexpression also affects Hülle cell formation, which is controlled by LaeA. Overproduction of SasA might affect LaeA function and subsequently methylation of histone-2B and secondary metabolite production (Fig. 7). Histone-3 trimethylation at lysine 9 had been found to be associated with the repression of secondary metabolism clusters in A. nidulans. LaeA is presumably involved in reversal of this heterochromatin signature inside the cluster (Reyes-Dominguez et al., 2010). The interaction of SasA with histone-2B is consistent with the finding that histone-2B can stimulate histone methyltransferase activity when modified at lysine 34 by ubiquitin (Wu et al., 2011). Future studies will elucidate whether LaeA epigenetic control includes not only the modulation of the histone-3 but also the histone-2B signature.

\section{Conclusions}

We present the first comprehensive study of the SAM synthetase SasA of the filamentous fungus A. nidulans. Our results support a complex SasA network of the major methyl group donor synthetase. SasA seems to be part of several protein complexes including methylation targets and associated proteins. SasA is involved in a variety of cellular processes and a precise balance of SasA levels is necessary to enable normal fungal morphogenesis, development and secondary metabolism. SasA contributes to methionine and other metabolic pathways, stress response, fungal morphogenesis and secondary metabolism. An interaction of SasA to histone-2B supports a SasA mediated link to epigenetic control by methylation.

\section{Acknowledgments}

We thank Sarah Henze for experimental support, Oliver Valerius for mass spectrometry identifications and Bastian Joehnk for proof-reading of the manuscript. This work has been funded by grants from the Deutsche Forschungsgemeinschaft (DFG), the German-Mexican FOR1334, the Volkswagen-Stiftung, and the Fonds der Chemischen Industrie to G.H.B.

\section{Appendix A. Supplementary material}

Supplementary data associated with this article can be found, in the online version, at http://dx.doi.org/10.1016/j.fgb.2012.04.003.

\section{References}

Adams, T.H., Wieser, J.K., Yu, J.H., 1998. Asexual sporulation in Aspergillus nidulans. Microbiol. Mol. Biol. Rev. 62, 35-54.

Amutha, B., Pain, D., 2003. Nucleoside diphosphate kinase of Saccharomyces cerevisiae, Ynk1p: localization to the mitochondrial intermembrane space. Biochem. J. 370, 805-815.

Arst Jr., H.N., Cove, D.J., 1973. Nitrogen metabolite repression in Aspergillus nidulans. Mol. Gen. Genet. 126, 111-141.

Barratt, R.W., Johnson, G.B., Ogata, W.N., 1965. Wild-type and mutant stocks of Aspergillus nidulans. Genetics 52, 233-246.

Bayram, O., Braus, G.H., 2011. Coordination of secondary metabolism and development in fungi: the velvet family of regulatory proteins. FEMS Microbiol. Rev. 36, 1-24.

Bayram, O., Krappmann, S., Ni, M., Bok, J.W., Helmstaedt, K., Valerius, O., BrausStromeyer, S., Kwon, N.J., Keller, N.P., Yu, J.H., Braus, G.H., 2008. VelB/VeA/LaeA complex coordinates light signal with fungal development and secondary metabolism. Science 320, 1504-1506.

Bayram, O., Braus, G.H., Fischer, R., Rodriguez-Romero, J., 2010. Spotlight on Aspergillus nidulans photosensory systems. Fungal Genet. Biol. 47, 900-908.
Belbahri, L., Chevalier, L., Bensaddek, L., Gillet, F., Fliniaux, M.A., Boerjan, W., Inze, D., Thomas, D. Thomasset B., 2000. Different expression of an Sadenosylmethionine synthetase gene in transgenic tobacco callus modifies alkaloid biosynthesis. Biotechnol. Bioeng. 69, 11-20.

Bjork, G.R., Ericson, J.U., Gustafsson, C.E., Hagervall, T.G., Jonsson, Y.H., Wikstrom, P.M., 1987. Transfer RNA modification. Annu. Rev. Biochem. 56, 263-287.

Boerjan, W., Bauw, G., Van Montagu, M., Inze, D., 1994. Distinct phenotypes generated by overexpression and suppression of S-adenosyl-L-methionine synthetase reveal developmental patterns of gene silencing in tobacco. Plant Cell. 6, 1401-1414.

Bok, J.W., Keller, N.P., 2004. LaeA, a regulator of secondary metabolism in Aspergillus spp. Eukaryot. Cell 3, 527-535.

Bok, J.W., Noordermeer, D., Kale, S.P., Keller, N.P., 2006. Secondary metabolic gene cluster silencing in Aspergillus nidulans. Mol. Microbiol. 61, 1636-1645.

Bowman, W.H., Tabor, C.W., Tabor, H., 1973. Spermidine biosynthesis. Purification and properties of propylamine transferase from Escherichia coli. J. Biol. Chem. $248,2480-2486$

Braus, G.H., Krappmann, S., Eckert, S.E., 2002. Sexual development in ascomycetes: fruit body formation of Aspergillus nidulans. In: Osiewacz, H.D. (Ed.), Molecular biology of fungal development. Marcel Dekker, Inc., New York, Basel, pp. 215-244.

Braus, G.H., Irniger, S., Bayram, O., 2010. Fungal development and the COP9 signalosome. Curr. Opin. Microbiol. 13, 672-676.

Brown, T., Mackey, K., 1997. Analysis of RNA by Northern and slot blot hybridization. In: Ausubel, F.M., Brent, R., Kingston, R.E., Moore, D.D., Seidmann, J.G., Smith, K. (Eds.), Current protocols in molecular biology. John Wiley and Sons, New York, pp. 4.9.1-4.9.16.

Busch, S., Eckert, S.E., Krappmann, S., Braus, G.H., 2003. The COP9 signalosome is an essential regulator of development in the filamentous fungus Aspergillus nidulans. Mol. Microbiol. 49, 717-730.

Cabrero, C., Duce, A.M., Ortiz, P., Alemany, S., Mato, J.M., 1988. Specific loss of the high-molecular-weight form of S-adenosyl-L-methionine synthetase in human liver cirrhosis. Hepatology 8, 1530-1534.

Cai, J., Sun, W.M., Hwang, J.J., Stain, S.C., Lu, S.C., 1996. Changes in Sadenosylmethionine synthetase in human liver cancer: molecular characterization and significance. Hepatology 24, 1090-1097.

Catoni, G.L., 1953. S-adenosylmethionine: a new intermediate formed enzymatically from L-methionine and adenosinetriphosphate. J. Biol. Chem. 204, 403-416.

Chant, J., Herskowitz, I., 1991. Genetic control of bud site selection in yeast by a set of gene products that constitute a morphogenetic pathway. Cell 65, 1203-1212.

Cherest, H., Surdin-Kerjan, Y., 1978. S-adenosyl methionine requiring mutants in Saccharomyces cerevisiae: evidences for the existence of two methionine adenosyl transferases. Mol. Gen. Genet. 163, 153-167.

Chiang, P.K., Gordon, R.K., Tal, J., Zeng, G.C., Doctor, B.P., Pardhasaradhi, K., McCann, P.P., 1996. S-Adenosylmethionine and methylation. FASEB J. 10, 471-480.

Cid, V.J., Duran, A., del Rey, F., Snyder, M.P., Nombela, C., Sanchez, M., 1995. Molecular basis of cell integrity and morphogenesis in Saccharomyces cerevisiae. Microbiol. Rev. 59, 345-386.

Clutterbuck, A.J., 1974. Aspergillus nidulans. In: King, R.C. (Ed.), Handbook of genetics. Plenum, New York, pp. 447-510.

Coleman, S.T., Fang, T.K., Rovinsky, S.A., Turano, F.J., Moye-Rowley, W.S., 2001. Expression of a glutamate decarboxylase homologue is required for normal oxidative stress tolerance in Saccharomyces cerevisiae. J. Biol. Chem. 276, 244-250.

Collins, S.R., Kemmeren, P., Zhao, X.C. Greenblatt, J.F., Spencer, F., Holstege, F.C., Weissman, J.S., Krogan, N.J., 2007. Toward a comprehensive atlas of the physical interactome of Saccharomyces cerevisiae. Mol. Cell. Proteomics 6, 439-450.

Corbino, K.A., Barrick, J.E., Lim, J., Welz, R., Tucker, B.J., Puskarz, I., Mandal, M., Rudnick, N.D., Breaker, R.R., 2005. Evidence for a second class of Sadenosylmethionine riboswitches and other regulatory RNA motifs in alphaproteobacteria. Genome Biol. 6, R70.

Corrales, F., Ochoa, P., Rivas, C., Martin-Lomas, M., Mato, J.M., Pajares, M.A., 1991. Inhibition of glutathione synthesis in the liver leads to S-adenosyl-L-methionine synthetase reduction. Hepatology 14, 528-533.

Corrales, F., Gimenez, A., Alvarez, L., Caballeria, J., Pajares, M.A., Andreu, H., Pares, A., Mato, J.M., Rodes, J., 1992. S-adenosylmethionine treatment prevents carbon tetrachloride-induced S-adenosylmethionine synthetase inactivation and attenuates liver injury. Hepatology 16, 1022-1027.

Cyert, M.S., 2001. Genetic analysis of calmodulin and its targets in Saccharomyces cerevisiae. Annu. Rev. Genet. 35, 647-672.

Deinert, K., Fasiolo, F., Hurt, E.C., Simos, G., 2001. Arc1p organizes the yeast aminoacyl-tRNA synthetase complex and stabilizes its interaction with the cognate tRNAs. J. Biol. Chem. 276, 6000-6008.

Duce, A.M., Ortiz, P., Cabrero, C., Mato, J.M., 1988. S-adenosyl-L-methionine synthetase and phospholipid methyltransferase are inhibited in human cirrhosis. Hepatology 8, 65-68.

Easlon, E., Tsang, F., Skinner, C., Wang, C., Lin, S.J., 2008. The malate-aspartate NADH shuttle components are novel metabolic longevity regulators required for calorie restriction-mediated life span extension in yeast. Genes Dev. 22, 931944.

Eckert, S.E., Kubler, E., Hoffmann, B., Braus, G.H., 2000. The tryptophan synthaseencoding $\operatorname{trpB}$ gene of Aspergillus nidulans is regulated by the cross-pathway control system. Mol. Gen. Genet. 263, 867-876.

Feinberg, A.P., Vogelstein, B., 1983. A technique for radiolabeling DNA restriction endonuclease fragments to high specific activity. Anal. Biochem. 132, 6-13.

Felsenstein, J., 1985. Confidence limits on phylogenies: An approach using the bootstrap. Evolution 39, 783-791. 
Galani, K., Grosshans, H., Deinert, K., Hurt, E.C., Simos, G., 2001. The intracellular location of two aminoacyl-tRNA synthetases depends on complex formation with Arc1p. EMBO J. 20, 6889-6898.

Gavin, A.C., Bosche, M., Krause, R., Grandi, P., Marzioch, M., Bauer, A., Schultz, J., Rick, J.M., Michon, A.M., Cruciat, C.M., Remor, M., Hofert, C., Schelder, M., Brajenovic, M., Ruffner, H., Merino, A., Klein, K., Hudak, M., Dickson, D., Rudi, T., Gnau, V. Bauch, A., Bastuck, S., Huhse, B., Leutwein, C., Heurtier, M.A., Copley, R.R., Edelmann, A., Querfurth, E., Rybin, V., Drewes, G., Raida, M., Bouwmeester, T. Bork, P., Seraphin, B., Kuster, B., Neubauer, G., Superti-Furga, G., 2002. Functional organization of the yeast proteome by systematic analysis of protein complexes. Nature 415, 141-147.

Gavin, A.C., Aloy, P., Grandi, P., Krause, R., Boesche, M., Marzioch, M., Rau, C., Jensen, L.J., Bastuck, S., Dumpelfeld, B., Edelmann, A., Heurtier, M.A., Hoffman, V. Hoefert, C., Klein, K., Hudak, M., Michon, A.M., Schelder, M., Schirle, M., Remor M., Rudi, T., Hooper, S., Bauer, A., Bouwmeester, T., Casari, G., Drewes, G. Neubauer, G., Rick, J.M., Kuster, B., Bork, P., Russell, R.B., Superti-Furga, G., 2006. Proteome survey reveals modularity of the yeast cell machinery. Nature 440 631-636.

Gong, Y., Kakihara, Y., Krogan, N., Greenblatt, J., Emili, A., Zhang, Z., Houry, W.A., 2009. An atlas of chaperone-protein interactions in Saccharomyces cerevisiae: implications to protein folding pathways in the cell. Mol. Syst. Biol. 5, 275.

Graham, D.E., Bock, C.L., Schalk-Hihi, C., Lu, Z.J., Markham, G.D., 2000. Identification of a highly diverged class of S-adenosylmethionine synthetases in the archaea. J. Biol. Chem. 275, 4055-4059.

Haarasilta, S., Oura, E., 1975. On the activity and regulation of anaplerotic and gluconeogenetic enzymes during the growth process of Baker's yeast. The biphasic growth. Eur. J. Biochem. 52, 1-7.

Hilti, N., Graub, R., Jorg, M., Arnold, P., Schweingruber, A.M., Schweingruber, M.E., 2000. Gene sam1 encoding adenosylmethionine synthetase: effects of its expression in the fission yeast Schizosaccharomyces pombe. Yeast 16, 1-10.

Ho, Y., Gruhler, A., Heilbut, A., Bader, G.D., Moore, L., Adams, S.L., Millar, A., Taylor, P., Bennett, K., Boutilier, K., Yang, L., Wolting, C., Donaldson, I., Schandorff, S. Shewnarane, J., Vo, M., Taggart, J., Goudreault, M., Muskat, B., Alfarano, C. Dewar, D., Lin, Z., Michalickova, K., Willems, A.R., Sassi, H., Nielsen, P.A., Rasmussen, K.J., Andersen, J.R., Johansen, L.E., Hansen, L.H., Jespersen, H. Podtelejnikov, A., Nielsen, E., Crawford, J., Poulsen, V., Sorensen, B.D. Matthiesen, J., Hendrickson, R.C., Gleeson, F., Pawson, T., Moran, M.F. Durocher, D., Mann, M., Hogue, C.W., Figeys, D., Tyers, M., 2002. Systematic identification of protein complexes in Saccharomyces cerevisiae by mass spectrometry. Nature 415, 180-183.

Kolar, M., Punt, P.J., van den Hondel, C.A., Schwab, H., 1988. Transformation of Penicillium chrysogenum using dominant selection markers and expression of an Escherichia coli lacZ fusion gene. Gene 62, 127-134.

Kozbial, P.Z., Mushegian, A.R., 2005. Natural history of S-adenosylmethioninebinding proteins. BMC Struct. Biol. 5, 19.

Krogan, N.J., Cagney, G., Yu, H., Zhong, G., Guo, X., Ignatchenko, A., Li, J., Pu, S., Datta, N., Tikuisis, A.P., Punna, T., Peregrin-Alvarez, J.M., Shales, M., Zhang, X., Davey, M., Robinson, M.D., Paccanaro, A., Bray, J.E., Sheung, A., Beattie, B., Richards, D.P., Canadien, V., Lalev, A., Mena, F., Wong, P., Starostine, A., Canete, M.M., Vlasblom, J., Wu, S., Orsi, C., Collins, S.R., Chandran, S., Haw, R., Rilstone, J.J., Gandi, K. Thompson, N.J., Musso, G., St Onge, P., Ghanny, S., Lam, M.H., Butland, G., AltafUl, A.M., Kanaya, S., Shilatifard, A., O'Shea, E., Weissman, J.S., Ingles, C.J., Hughes, T.R., Parkinson, J., Gerstein, M., Wodak, S.J., Emili, A., Greenblatt, J.F., 2006. Global landscape of protein complexes in the yeast Saccharomyces cerevisiae. Nature 440, 637-643.

Kumar, A., Agarwal, S., Heyman, J.A., Matson, S., Heidtman, M., Piccirillo, S. Umansky, L., Drawid, A., Jansen, R., Liu, Y., Cheung, K.H., Miller, P., Gerstein, M. Roeder, G.S., Snyder, M., 2002. Subcellular localization of the yeast proteome. Genes Dev. 16, 707-719.

Loenen, W.A., 2006. S-adenosylmethionine: jack of all trades and master of everything? Biochem. Soc. Trans. 34, 330-333.

Malkowski, M.G., Quartley, E., Friedman, A.E., Babulski, J., Kon, Y., Wolfley, J., Said, M., Luft, J.R., Phizicky, E.M., DeTitta, G.T., Grayhack, E.J., 2007. Blocking Sadenosylmethionine synthesis in yeast allows selenomethionine incorporation and multiwavelength anomalous dispersion phasing. Proc. Natl. Acad. Sci. USA 104, 6678-6683.

Markham, G.D., Hafner, E.W., Tabor, C.W., Tabor, H., 1983. S-adenosylmethionine synthetase (methionine adenosyltransferase) (Escherichia coli). Methods Enzymol. 94, 219-222.

Marobbio, C.M., Agrimi, G., Lasorsa, F.M., Palmieri, F., 2003. Identification and functional reconstitution of yeast mitochondrial carrier for Sadenosylmethionine. EMBO J. 22, 5975-5982.

Mato, J.M., Alvarez, L., Ortiz, P., Pajares, M.A., 1997. S-adenosylmethionine synthesis: molecular mechanisms and clinical implications. Pharmacol. Ther. 73, 265-280.

Mautino, M.R., Barra, J.L., Rosa, A.L., 1996. Eth-1, the Neurospora crassa locus encoding S-adenosylmethionine synthetase: molecular cloning, sequence analysis and in vivo overexpression. Genetics 142, 789-800.

McDaniel, B.A., Grundy, F.J., Henkin, T.M., 2005. A tertiary structural element in S box leader RNAs is required for S-adenosylmethionine-directed transcription termination. Mol. Microbiol. 57, 1008-1021.

Mudd, S.H., Cantoni, G.L., 1958. Activation of methionine for transmethylation. III. The methionine-activating enzyme of Bakers' yeast. J. Biol. Chem. 231, 481-492.

Nayak, T., Szewczyk, E., Oakley, C.E., Osmani, A., Ukil, L., Murray, S.L., Hynes, M.J., Osmani, S.A., Oakley, B.R., 2006. A versatile and efficient gene-targeting system for Aspergillus nidulans. Genetics 172, 1557-1566.
Nei, M., Kumar, S. (Eds.), 2000. Molecular Evolution and Phylogenetics. Oxford University Press, New York.

Newman, E.B., Budman, L.I., Chan, E.C., Greene, R.C., Lin, R.T., Woldringh, C.L., D’Ari, R., 1998. Lack of S-adenosylmethionine results in a cell division defect in Escherichia coli. J. Bacteriol. 180, 3614-3619.

Ochi, K., Freese, E., 1982. A decrease in S-adenosylmethionine synthetase activity increases the probability of spontaneous sporulation. J. Bacteriol 152,400-410.

Pajares, M.A., Corrales, F.J., Ochoa, P., Mato, J.M., 1991. The role of cysteine-150 in the structure and activity of rat liver S-adenosyl-L-methionine synthetase. Biochem. J. 274 (Pt 1), 225-229.

Peleman, J., Saito, K., Cottyn, B., Engler, G., Seurinck, J., Van Montagu, M., Inze, D. 1989. Structure and expression analyses of the S-adenosylmethionine synthetase gene family in Arabidopsis thaliana. Gene 84, 359-369.

Pfaffl, M.W., Horgan, G.W., Dempfle, L., 2002. Relative expression software too REST) for group-wise comparison and statistical analysis of relative expression results in real-time PCR. Nucleic Acids Res. 30, e36.

Pieniazek, N.J., Kowalska, I.M., Stepien, P.P., 1973. Deficiency in methionine adenosyltransferase resulting in limited repressibility of methionine biosynthetic enzymes in Aspergillus nidulans. Mol. Gen. Genet. 126, 367-374.

Porcelli, M., Cacciapuoti, G., Carteni-Farina, M., Gambacorta, A., 1988. Sadenosylmethionine synthetase in the thermophilic archaebacterium Sulfolobus solfataricus. Purification and characterization of two isoforms. Eur. J. Biochem. 177, 273-280.

Pruyne, D., Bretscher, A., 2000. Polarization of cell growth in yeast. J. Cell Sci. 113 (Pt 4), 571-585.

Punt, P.J., van den Hondel, C.A., 1992. Transformation of filamentous fungi based on hygromycin B and phleomycin resistance markers. Methods Enzymol. 216, 447-457.

Punt, P.J., Strauss, J., Smit, R., Kinghorn, J.R., van den Hondel, C.A., Scazzocchio, C., 1995. The intergenic region between the divergently transcribed niiA and niaD genes of Aspergillus nidulans contains multiple NirA binding sites which act bidirectionally. Mol. Cell. Biol. 15, 5688-5699.

Purschwitz, J., Muller, S., Kastner, C., Schoser, M., Haas, H., Espeso, E.A., Atoui, A., Calvo, A.M., Fischer, R., 2008. Functional and physical interaction of blue- and red-light sensors in Aspergillus nidulans. Curr. Biol. 18, 255-259.

Reyes-Dominguez, Y., Bok, J.W., Berger, H., Shwab, E.K., Basheer, A., Gallmetzer, A., Scazzocchio, C., Keller, N., Strauss, J., 2010. Heterochromatic marks are associated with the repression of secondary metabolism clusters in Aspergillus nidulans. Mol. Microbiol. 76, 1376-1386.

Saitou, N., Nei, M., 1987. The neighbor-joining method: a new method for reconstructing phylogenetic trees. Mol. Biol. Evol. 4, 406-425.

Sakata, S.F., Shelly, L.L., Ruppert, S., Schutz, G., Chou, J.Y., 1993. Cloning and expression of murine S-adenosylmethionine synthetase. J. Biol. Chem. 268 13978-13986.

Sanders, S.L., Herskowitz, I., 1996. The BUD4 protein of yeast, required for axial budding, is localized to the mother/BUD neck in a cell cycle-dependent manner. J. Cell Biol. 134, 413-427.

Sarikaya Bayram, O., Bayram, O., Valerius, O., Park, H.S., Irniger, S., Gerke, J., Ni, M., Han, K.H., Yu, J.H., Braus, G.H., 2010. LaeA control of velvet family regulatory proteins for light-dependent development and fungal cell-type specificity. PLoS Genet. 6, e1001226.

Schatz, P.J., Solomon, F., Botstein, D., 1986. Genetically essential and nonessential alpha-tubulin genes specify functionally interchangeable proteins. Mol. Cell. Biol. 6, 3722-3733.

Shevchenko, A., Wilm, M., Vorm, O., Mann, M., 1996. Mass spectrometric sequencing of proteins silver-stained polyacrylamide gels. Anal. Chem. 68, 850-858.

Tabor, C.W., Tabor, H., 1984. Methionine adenosyltransferase (Sadenosylmethionine synthetase) and S-adenosylmethionine decarboxylase. Adv. Enzymol. Relat. Areas Mol. Biol. 56, 251-282.

Takusagawa, F., Kamitori, S., Misaki, S., Markham, G.D., 1996a. Crystal structure of Sadenosylmethionine synthetase. J. Biol. Chem. 271, 136-147.

Takusagawa, F., Kamitori, S., Markham, G.D., 1996b. Structure and function of Sadenosylmethionine synthetase: crystal structures of S-adenosylmethionine synthetase with ADP, BrADP, and PPi at 28 angstroms resolution. Biochemistry 35, 2586-2596.

Tamura, K., Peterson, D., Peterson, N., Stecher, G., Nei, M., Kumar, S., 2011. MEGA5 molecular evolutionary genetics analysis using maximum likelihood, evolutionary distance, and maximum parsimony methods. Mol. Biol. Evol. 28, 2731-2739.

Thomas, D., Surdin-Kerjan, Y., 1987. SAM1, the structural gene for one of the Sadenosylmethionine synthetases in Saccharomyces cerevisiae. Sequence and expression. J. Biol. Chem. 262, 16704-16709.

Thomas, D., Surdin-Kerjan, Y., 1991. The synthesis of the two S-adenosylmethionine synthetases is differently regulated in Saccharomyces cerevisiae. Mol. Gen. Genet. 226, 224-232.

Wang, S., Arends, S.J., Weiss, D.S., Newman, E.B., 2005. A deficiency in Sadenosylmethionine synthetase interrupts assembly of the septal ring in Escherichia coli K-12. Mol. Microbiol. 58, 791-799.

Winkler, W.C., Breaker, R.R., 2005. Regulation of bacterial gene expression by riboswitches. Annu. Rev. Microbiol. 59, 487-517.

Wu, L., Zee, B.M., Wang, Y., Garcia, B.A., Dou, Y., 2011. The RING finger protein MSL2 in the MOF complex is an E3 ubiquitin ligase for H2B K34 and is involved in crosstalk with H3 K4 and K79 methylation. Mol. Cell 43, 132-144.

Yarlett, N., Garofalo, J., Goldberg, B., Ciminelli, M.A., Ruggiero, V., Sufrin, J.R., Bacchi, C.J., 1993. S-adenosylmethionine synthetase in bloodstream Trypanosoma brucei. Biochim. Biophys. Acta 1181, 68-76. 